\title{
ASPECTS OF MULTICRITERIAL MATHEMATICAL MODELING AND OF THE FUZZY FORMALISM FOR THE HIERARCHIZATION OF STUDY PROGRAMS BASED ON SEVERAL QUALITY CHARACTERISTICS
}

\author{
AMELIA BUCUR, Assoc. Prof. Ph.D., \\ Faculty of Sciences/ Department of Mathematics and Informatics, \\ "Lucian Blaga" University of Sibiu, Sibiu, Romania, \\ e-mail: amelia.bucur@ulbsibiu.ro
}

\begin{abstract}
The aim of this paper is to present aspects of mathematical modeling for the hierarchization of study programs from universities, based on several quality characteristics. The tools used pertain to multicriterial optimization, to the different methods of assessing importance coefficients, to the utility theory, the fuzzy formalism, and to the fuzzy simple additive weighting method. The conclusion is that multicriterial decision-making methods can be efficiently used in assessing the quality of study programs, noting that, just like other methods from the decision theory, the multicriterial decision-making methods highlight aspects of problems differently, therefore, there can be no comparison or competitiveness between them, and choosing one over the other is up to the decisionmaker.
\end{abstract}

Key words: multicriterial optimization, fuzzy, quality

\section{Introduction}

The topics of quality in higher education, of assuring quality in higher education, of study programs in universities and their hierarchization are of great interest and are highly debated in the specialty literature. [1]

In the paper Modeling as a Multiple-Criteria Decision-Making Problem and Simulation, for the Hierarchization of Programs of Study [2] the author presented a way of approaching the problem of hierarchization of study programs in universities as a multicriterial decision-making problem. The importance coefficients were chosen randomly, in order to exemplify the applications of the mathematical tools. These coefficients can be chosen by the decision-maker based on the objectives of the organizations they are part of, and according to their managerial experience.

In sections 2 and 3 of the current paper, the author presents a way of using multicriterial optimization methods in order to obtain results regarding the hierarchization of study programs, by choosing the importance coefficients after assessing them through various methods (the eigenvector method, the least squares method, the entropy method).

On the other hand, fuzzy formalism has proven to be efficient in modeling systems in conditions of uncertainty, by replacing or completing probabilistic methods. [3]

Fuzzy logic has been applied in many traditional problems, and recently it has also been applied in fields such as information technology, telecommunications, electrotechnics, traffic control, and in quality management. In terms of quality management, fuzzy systems have been applied in the dynamic of global standardization processes. [4]

The fuzzy set theory is known by many researchers and managers as a method that can provide modern tools for solving numerous problems that deal with quality management, and it is also a promising technique in the case of processes that contain unreliable data. [5]

In section 4 of this paper, the author presents a method of applying fuzzy simple additive weighting in the field of quality management.

\section{Mathematical modeling}


Firstly, the mathematical modeling of the hierarchization of study programs involves the use of a matrix, known in the specialty literature as decision matrix or consequence matrix [6], $A$, which has the following elements, included in Table 1:

Table 1: Decision matrix for a multicriterial problem

\begin{tabular}{|c|c|c|c|c|c|}
\hline Criteria of decision & $C_{1}$ & $\ldots$ & $C_{j}$ & $\ldots$ & $C_{n}$ \\
\hline $\begin{array}{c}\text { Coefficients of } \\
\text { importance }\end{array}$ & $k_{1}$ & $\ldots$ & $k_{j}$ & $\ldots$ & $k_{n}$ \\
\hline$V_{1}$ & $a_{11}$ & $\ldots$ & $a_{1 j}$ & $\ldots$ & $a_{1 n}$ \\
\hline$V_{2}$ & $a_{21}$ & $\ldots$ & $a_{2 j}$ & $\ldots$ & $a_{2 n}$ \\
\hline$\ldots$ & $\ldots$ & $\ldots$ & $\ldots$ & $\ldots$ & $\ldots$ \\
\hline$V_{i}$ & $a_{i 1}$ & $\ldots$ & $a_{i j}$ & $\ldots$ & $a_{i n}$ \\
\hline$\ldots$ & $\ldots$ & $\ldots$ & $\ldots$ & $\ldots$ & $\ldots$ \\
\hline$V_{m}$ & $a_{m 1}$ & $\ldots$ & $a_{m j}$ & $\ldots$ & $a_{m n}$ \\
\hline
\end{tabular}

where: $V_{i}=i$ variant/alternative , for $i=1,2,3 \ldots \ldots . . m$; $C_{j}-j$ criterion for $j=1,2,3 \ldots . . . n$; $k_{j}$ - importance criterion $\left(j\right.$ criterion weight) for $j=1,2,3 . . . n$; $a_{i j}-i$ alternative consequence (performance) for the $j$ criterion.

In order to evaluate importance coefficients, the following methods may be used: eigenvector method, the least squares method, the entropy method, the Linear Programming Techniques for Multidimensional Analysis of Preference method, the scores method, the statistical analysis method etc.[7] A more detailed explanation about the first three methods can be found in the following subsections.

\subsection{The eigenvector method.}

The vector for the importance coefficients, $K=\left(k_{1}, \ldots, k_{n}\right)$, with $\sum_{i=1}^{n} k_{i}=1$, contains in each one of its elements the importance given by the decision-maker to each criterion.

The assessment of the coefficients can be made through several methods that take into consideration the relative importance of the criteria, which is established in the following matrix:

$$
K_{r}=\left(\begin{array}{ccc}
\frac{k_{1}}{k_{1}} & \frac{k_{1}}{k_{2}} \ldots & \frac{k_{1}}{k_{n}} \\
\ldots & \ldots & \ldots \\
\frac{k_{n}}{k_{1}} & \frac{k_{n}}{k_{2}} \ldots & \frac{k_{n}}{k_{n}}
\end{array}\right) .
$$

By calculating $K_{r} K^{T}=\lambda K^{T}$, we obtain that $K^{T}$ is the eigenvector of matrix $K_{r}$.

Thus, by using the eigenvector method, we obtain that $K$ is an eigenvector associated to the highest of the eigenvalues of matrix $K_{r}$.

The specialty literature [8] uses a scale of importance for the relative importance $k_{i j} \equiv \frac{k_{i}}{k_{j}}$ from matrix $K_{r}$, as shown in the following table:

Table 2: Scale for the relative importance of the criteria

\begin{tabular}{|c|l|l|}
\hline $\begin{array}{c}\text { Intensity of the } \\
\text { relative importance } \\
\frac{\boldsymbol{k}_{\boldsymbol{i}}}{\boldsymbol{k}_{\boldsymbol{j}}}\end{array}$ & \multicolumn{1}{|c|}{$\begin{array}{c}\text { Interpretation of the } \\
\text { criteria's importance }\end{array}$} & Motivation \\
\hline 1 & Equal importance & Criteria $C_{i}$ and $C_{i}$ contribute equally to the objective \\
\hline 3 & Low importance & $\begin{array}{l}\text { Personal experience shows a slightly higher importance } \\
\text { of one of the criteria over the other }\end{array}$ \\
\hline 5 & High importance & $\begin{array}{l}\text { Personal experience shows a higher importance of one of } \\
\text { the criteria over the other }\end{array}$ \\
\hline 7 & Proved importance & $\begin{array}{l}\text { Practice proved the higher importance of one of the } \\
\text { criteria over the other }\end{array}$ \\
\hline 9 & Absolute importance & $\begin{array}{l}\text { One of the criteria is evidently more important than the } \\
\text { other }\end{array}$ \\
\hline $2,4,6,8$ & $\begin{array}{l}\text { Importance of intermediate } \\
\text { values }\end{array}$ & Used when a compromise is necessary \\
\hline
\end{tabular}




\subsection{Least squares method.}

The method uses the same matrix $K_{r}$ from formula (1). The established condition is that the sum of square distances between the theoretical importance coefficients and the importance coefficients expressed by the relative importance $k_{i j} \equiv \frac{k_{i}}{k_{j}}$ should be minimum:

$$
\left\{\begin{array}{c}
\min \sum_{i=1}^{n} \sum_{j=1}^{n}\left(k_{i j} k_{j}-k_{i}\right)^{2} \\
\sum_{i=1}^{n} k_{i}=1, \quad k_{i}>0, \quad i=\overline{1, n}
\end{array} .\right.
$$

In this case, the Lagrange function may be written as:

$$
L=\sum_{i=1}^{n} \sum_{j=1}^{n}\left(k_{i j} k_{j}-k_{i}\right)^{2}+2 \lambda\left(\sum_{i=1}^{n} p_{i}-1\right) .
$$

By differentiating this function with respect to each importance coefficient $k_{s}$, and then by equating the derivatives to zero we obtain a system of $n+1$ linear equations with $n+1$ unknowns:

$$
\left\{\begin{array}{c}
2 \sum_{i=1}^{n}\left(k_{i s} k_{s}-k_{i}\right) k_{i s}-2 \sum_{j=1}^{n}\left(k_{s j} k_{j}-k_{s}\right)+2 \lambda=0, s=\overline{1, n} \\
\sum_{i=1}^{n} k_{i}=1
\end{array} .\right.
$$

The solutions to this system are the importance coefficients $k_{1}, \ldots, k_{n}$ and the Lagrange multiplier $\lambda$.

\subsection{The entropy method.}

This method uses the consequence matrix $A$, with elements $a_{i j}$ from Table 1 , and the entropy $H$ as measure of uncertainty of the probability distribution $k_{1}, \ldots, k_{n}$ :

where $c$ is a real number.

$$
H\left(k_{1}, \ldots, k_{n}\right)=-c \sum_{j=1}^{n} k_{j} \ln k_{j},
$$

We calculate the normalized results of criterion $C_{j}$ for each $j=\overline{1, n}$ :

$$
r_{i j}=\frac{a_{i j}}{\sum_{i=1}^{m} a_{i j}}, \quad i=\overline{1, m} \text {. }
$$

The entropy $H_{j}$ of the set of normalized results for criterion $C_{j}$ is:

The importance coefficients are:

$$
H_{j}=-\frac{1}{\operatorname{lnm}} \sum_{i=1}^{m} r_{i j} \ln r_{i j} .
$$

$$
k_{j}=\frac{1-H_{j}}{\sum_{j=1}^{n}\left(1-H_{j}\right)}, j=\overline{1, n} .
$$

\section{Application of section 2.}

The criteria that we consider to be relevant to study programs are: $C_{1}=$ quality level of lectures; $C_{2}=$ quality level of laboratory classes; $C_{3}=$ student satisfaction level.

The importance coefficients of the criteria are assumed to be: $k_{1}, k_{2}, k_{3}$, and are determined successively with the three methods of assessing importance coefficients mentioned in subsections 2.1, 2.2, and 2.3.

The study programs (various programs within the same institution, or the same program in different universities) may be: $V_{1}\left(P_{1}\right)=$ study program $1 ; V_{2}\left(P_{2}\right)=$ study program $2 ; V_{3}\left(P_{3}\right)=$ study program 3.

Elements $a_{i j}$ within the matrices in Table 1 represent, in this case, a product between the level of the values attributed to the $C_{j}$ criterion on a 1 to 5 Likert scale, namely $N_{i}\left(C_{j}\right)$ and the importance coefficients $k_{j}$. This product can be calculated using the formula:

$$
a_{i j}=N_{i}\left(C_{j}\right) k_{j} \text {, where } i=1,2,3 \text { and } j=1,2,3 \text {. }
$$

This estimation of the values is subjective and dependant on the manager's or program organizers' experience:

Table 3: Levels of values $N_{i}\left(C_{j}\right)$ attributed to $C_{j}$ criteria on a 1 to 5 Likert scale

\begin{tabular}{|c|c|c|c|}
\hline $\begin{array}{c}\text { Criteria of } \\
\text { decision }\end{array}$ & $C_{1}$ & $C_{2}$ & $C_{3}$ \\
\hline $\begin{array}{c}\text { Coefficients of } \\
\text { importance }\end{array}$ & $k_{1}$ & $k_{2}$ & $k_{3}$ \\
\hline$V_{1}\left(P_{1}\right)$ & 1 & 5 & 4 \\
\hline$V_{2}\left(P_{2}\right)$ & 5 & 3 & 2 \\
\hline$V_{3}\left(P_{3}\right)$ & 3 & 4 & 3 \\
\hline
\end{tabular}

Elements $a_{i j}$, the utilities and the synthesis utilities can be automatically calculated and displayed by the Microsoft Excel program for each of the methods 2.1, 2.2, 2.3 (Table 4): 
Table 4: Utility matrices for the multicriterial problem under discussion

\begin{tabular}{|c|c|c|c|c|c|c|c|c|c|c|c|c|c|c|c|c|c|}
\hline \multicolumn{6}{|c|}{ Method 2.1. } & \multicolumn{6}{|c|}{ Method 2.2. } & \multicolumn{6}{|c|}{ Method 2.3. } \\
\hline 19 & & $\mathrm{C1}$ & $\mathrm{C2}$ & $\overline{C 3}$ & & 19 & & $\overline{C 1}$ & $\mathrm{C2}$ & $\overline{C 3}$ & & 19 & & $\mathrm{C1}$ & $\mathrm{C2}$ & C3 & \\
\hline 20 & K & 0,1571 & 0,5936 & 0,2493 & & 20 & $K$ & 0,1735 & 0,0059 & 0,2206 & & 20 & $K$ & 0,129 & 0,509 & 0,362 & \\
\hline 21 & V1 & 0,00 & 1,00 & 1,00 & 0,84 & 21 & V1 & 0,00 & 1,00 & 1,00 & 0,23 & 21 & V1 & 0,00 & 1,00 & 1,00 & 0,87 \\
\hline 22 & V2] & 1,00 & 0,00 & 0,00 & 0,16 & 22 & $V_{2}$ & 1,00 & 0,00 & 0,00 & 0,17 & 22 & V2 & 1,00 & 0,00 & 0,00 & 0,13 \\
\hline 23 & V3] & 0,50 & 0,50 & 0,63 & 0,53 & 23 & V3 & 0,50 & 0,50 & 0,59 & 0,22 & 23 & V3 & 0,50 & 0,50 & 0,70 & 0,57 \\
\hline
\end{tabular}

As a conclusion, from the 4th column it can be inferred that the hierarchization of the study programs (of the variants) is the following: $V_{1}\left(P_{1}\right)$ program of study $=$ the optimum variant; $V_{3}\left(P_{3}\right)$ program of study; $V_{2}\left(P_{2}\right)$ program of study.

\section{Simple additive weighting method}

Simple Additive Weighting is one of the most popular methods in MADM problems [9]. Churchman and Ackoff (1945) were the first to use the Simple Additive Weighting method.

Firstly, this method establishes the normalized matrix associated to the decision matrix $\mathrm{A}=\left(a_{i j}\right)$. The normalized matrix will be used to calculate and compare the synthesis utilities of the variants.

The normalized matrix is $R=\left(r_{i j}\right)$, where:

$$
r_{i j}=\left\{\begin{array}{l}
\frac{a_{i j}}{\max _{i} a_{i j}}, \text { for maximum criteria, } \\
\frac{\min _{i} a_{i j}}{a_{i j}}, \text { for minimum criteria. }
\end{array}\right.
$$

The idea of the method is to define the function ([1]):

$$
f: V \rightarrow R, \quad f\left(V_{i}\right)=\frac{\sum_{j=1}^{n} k_{j} r_{i j}}{\sum_{j=1}^{n} k_{j}}=\sum_{j=1}^{n} w_{j} r_{i j}, \quad w_{j}=\frac{k_{j}}{\sum_{j=1}^{n} k_{j}}, j=1, \ldots, n .
$$

Function $f$ assigns a value to each variant $V_{i}, i=1, \ldots, m$. The variants can then be classified by using the values assigned to the variants by function $f$. The optimal variant will be the one for which $f\left(V_{i}\right)$ is maximum.

The method uses the following steps [10]: determining the criteria that will be used as a reference in decision-making, namely $C_{j}$; determining $k$ for each variant with respect to each criterion; establishing the decision matrix based on criteria $C_{j}$; obtaining the normalized matrix $R$; obtaining the final results by calculating a weighted sum, where the weights are components of vector $w=\left(w_{1}, \ldots, w_{1}\right)$, which are multiplied by elements $r_{i j}$ from the normalized matrix, for each $V_{i}$ variant.

\section{Application.}

In order to apply this method for the hierarchization of five variants of study programs with

\begin{tabular}{|c|c|c|c|c|c|c|c|c|}
\hline 4 & A & B & C & D & $E$ & $\mathrm{~F}$ & G & $\mathrm{H}$ \\
\hline \multicolumn{9}{|l|}{1} \\
\hline 2 & & C1 & $\mathrm{C} 2$ & C3 & C4 & C5 & C6 & \\
\hline 3 & $\mathrm{~K}$ & 1 & 0,8 & 0,6 & 0,2 & 0,4 & 0,8 & \\
\hline 4 & V1 & 1,00 & 0,60 & 0,50 & 0,90 & 0,60 & 0,90 & \\
\hline 5 & $\mathrm{v} 2$ & 0,75 & 0,80 & 0,75 & 0,60 & 0,60 & 0,30 & \\
\hline 6 & V3 & 0,75 & 0,80 & 0,50 & 0,60 & 0,60 & 0,30 & \\
\hline 7 & V4 & 0,75 & 0,40 & 0,50 & 0,90 & 0,60 & 0,30 & \\
\hline 8 & v5 & 1,00 & 0,40 & 0,75 & 0,90 & 0,60 & 0,60 & \\
\hline \multicolumn{9}{|l|}{9} \\
\hline \multicolumn{9}{|l|}{10} \\
\hline 11 & & C1 & C2 & C3 & C4 & C5 & C6 & \\
\hline 12 & $\mathrm{~K}$ & 1 & 0,8 & 0,6 & 0,2 & 0,4 & 0,8 & \\
\hline 13 & v1 & 1,00 & 0,75 & 0,67 & 1,00 & 1,00 & 1,00 & 3,40 \\
\hline 14 & v2 & 0,75 & 1,00 & 1,00 & 0,67 & 1,00 & 0,33 & 2,95 \\
\hline 15 & V3 & 0,75 & 1,00 & 0,67 & 0,67 & 1,00 & 0,33 & 2,75 \\
\hline 16 & V4 & 0,75 & 0,50 & 0,67 & 1,00 & 1,00 & 0,33 & 2,42 \\
\hline 17 & v5 & 1,00 & 0,50 & 1,00 & 1,00 & 1,00 & 0,67 & 3,13 \\
\hline \multicolumn{9}{|l|}{18} \\
\hline \multicolumn{9}{|l|}{19} \\
\hline 20 & V1 & 3,40 & & & & & & \\
\hline 21 & v2 & 2,95 & & & & & & \\
\hline 22 & v3 & 2,75 & & & & & & \\
\hline 23 & V4 & 2,42 & & & & & & \\
\hline 24 & v5 & 3,13 & & & & & & \\
\hline \multicolumn{9}{|l|}{25} \\
\hline \multicolumn{9}{|l|}{26} \\
\hline 27 & & \multicolumn{3}{|c|}{$\max \{\mathrm{V} 1, \ldots, \mathrm{V} 5\}$ este } & 3,40 & & & \\
\hline
\end{tabular}
respect to six quality characteristics, we create a file in Microsoft Excel:

Figure 1: Simulation in Microsoft Excel 


\section{The fuzzy simple additive weighting method}

The fuzzy simple additive weighting method is a generalization. In this case, matrix $A$ of assessing variants with respect to the criteria is a matrix of membership functions $\boldsymbol{\mu}_{\boldsymbol{a}_{\boldsymbol{i}}}:[\mathbf{0}, \mathbf{1}] \rightarrow \boldsymbol{R}$. Thus, Table 1 is generalized as Table 5: [10]

Table 5: The matrix for assessing variants/alternatives with respect to the criteria

\begin{tabular}{|c|c|c|c|c|c|}
\hline $\begin{array}{c}\text { Criteria of } \\
\text { decision }\end{array}$ & $C_{1}$ & $\ldots$ & $C_{j}$ & $\ldots$ & $C_{n}$ \\
\hline $\begin{array}{c}\text { Coefficients of } \\
\text { importance }\end{array}$ & $k_{1}$ & $\ldots$ & $k_{j}$ & $\ldots$ & $k_{n}$ \\
\hline$V_{1}$ & $\boldsymbol{\mu}_{\boldsymbol{a}_{11}}$ & $\ldots$ & $\boldsymbol{\mu}_{\boldsymbol{a}_{1 j}}$ & $\ldots$ & $\boldsymbol{\mu}_{\boldsymbol{a}_{1 n}}$ \\
\hline$V_{2}$ & $\boldsymbol{\mu}_{\boldsymbol{a}_{21}}$ & $\ldots$ & $\boldsymbol{\mu}_{\boldsymbol{a}_{2 j}}$ & $\ldots$ & $\boldsymbol{\mu}_{\boldsymbol{a}_{2 n}}$ \\
\hline$\ldots$ & $\ldots$ & $\ldots$ & $\ldots$ & $\ldots$ & $\ldots$ \\
\hline$V_{i}$ & $\boldsymbol{\mu}_{\boldsymbol{a}_{\boldsymbol{i}}}$ & $\ldots$ & $\boldsymbol{\mu}_{\boldsymbol{a}_{i j}}$ & $\ldots$ & $\boldsymbol{\mu}_{\boldsymbol{a}_{i n}}$ \\
\hline$\ldots$ & $\ldots$ & $\ldots$ & $\ldots$ & $\ldots$ & $\ldots$ \\
\hline$V_{m}$ & $\boldsymbol{\mu}_{\boldsymbol{a}_{\boldsymbol{m}}}$ & $\ldots$ & $\boldsymbol{\mu}_{\boldsymbol{a}_{\boldsymbol{m}}}$ & $\ldots$ & $\boldsymbol{\mu}_{\boldsymbol{a}_{\boldsymbol{m}}}$ \\
\hline
\end{tabular}

Another method, the maximin method, chooses as optimal variant the variant $\boldsymbol{V}_{\boldsymbol{i}_{\mathbf{0}}}$, with the following property:

$$
\mu_{a_{i_{0} j}}=\max _{i} \min _{j} \mu_{a_{i j}},
$$

where max and min are operations with fuzzy sets.

\section{Application of the fuzzy simple additive weighting method.}

For $k_{1}=\frac{1}{6}, k_{2}=\frac{1}{6}, k_{3}=\frac{2}{3}$ and the following membership functions:

$$
\begin{aligned}
& \mu_{11}(x)=\left\{\begin{array}{c}
2 x, x \in\left[0, \frac{1}{2}\right] \\
\left.-2 x+2, x \in] \frac{1}{2}, 1\right] \\
0, x \in R-[0,1]
\end{array}=\mu_{33}(x), \quad \mu_{12}(x)=\left\{\begin{array}{c}
3 x, x \in\left[0, \frac{1}{3}\right] \\
\left.\left.-\frac{3 x}{2}+\frac{3}{2}, x \in\right] \frac{1}{3}, 1\right]=\mu_{21}(x), \\
0, x \in R-[0,1]
\end{array}\right.\right.
\end{aligned}
$$

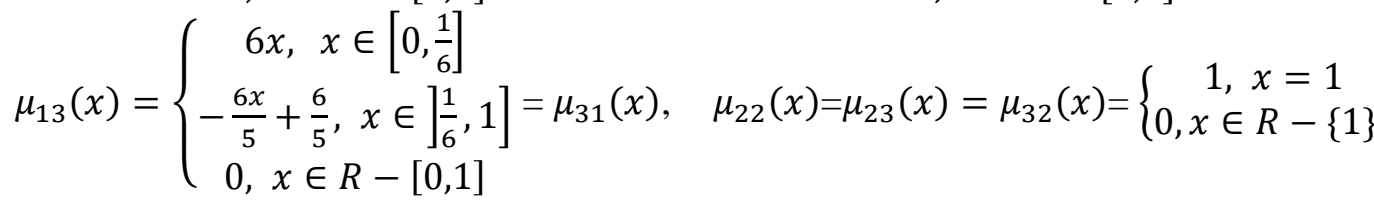

we have:

$$
\begin{aligned}
& f_{1}(x)=\frac{1}{6} \mu_{11}(x)+\frac{1}{6} \mu_{12}(x)+\frac{2}{3} \mu_{13}(x)=\left\{\begin{array}{c}
\frac{29 x}{6}, x \in\left[0, \frac{1}{6}\right] \\
\left.\left.\frac{-x+24}{30}, x \in\right] \frac{1}{6}, \frac{1}{3}\right] \\
\left.\left.\frac{-43 x}{60}+\frac{21}{20}, x \in\right] \frac{1}{3}, \frac{1}{2}\right], \\
\left.\left.\frac{-59 x+83}{60}, x \in\right] \frac{1}{2}, 1\right] \\
0, x \in R-[0,1]
\end{array}\right. \\
& f_{2}(x)=\frac{1}{6} \mu_{21}(x)+\frac{1}{6} \mu_{22}(x)+\frac{2}{3} \mu_{23}(x)=\left\{\begin{array}{c}
\frac{x}{2}, x \in\left[0, \frac{1}{3}\right] \\
\left.\frac{-x+4}{4}, x \in\right] \frac{1}{3}, 1[ \\
\frac{5}{6}, x \in\{1\} \\
0, x \in R-[0,1]
\end{array},\right. \\
& f_{3}(x)=\frac{1}{6} \mu_{31}(x)+\frac{1}{6} \mu_{32}(x)+\frac{2}{3} \mu_{33}(x)=\left\{\begin{array}{c}
\frac{7 x}{3}, x \in\left[0, \frac{1}{6}\right] \\
\left.\left.\frac{2 x+3}{15}, x \in\right] \frac{1}{6}, \frac{1}{2}\right] \\
\left.\frac{-23 x+17}{15}, x \in\right] \frac{1}{2}, 1[. \\
\frac{1}{6}, x \in\{1\} \\
0, x \in R-[0,1]
\end{array}\right.
\end{aligned}
$$

Because in formula (13), $\boldsymbol{f}_{\mathbf{3}}<\boldsymbol{f}_{\mathbf{1}}<\boldsymbol{f}_{\mathbf{2}}$, we obtain that $V_{2}$ is the optimum variant. 


\section{Conclusions}

Multicriterial decision-making methods can be efficiently used in assessing the quality of study programs, noting that, just like other methods from the decision theory, they highlight aspects of problems differently. Therefore, there cannot be comparison or competitiveness between these methods, and choosing one over the other is up to the decision-maker.

Fuzzy formalism grants more certainty in solving problems faced by quality management. The processes and systems based on fuzzy logic have exceptional capabilities in cases of incomplete or imprecise information, thus proving a high applicative potential in the field of quality management. Fuzzy logic may be able to offer the necessary mathematical support for modeling uncertainty that it sometimes specific to the field of quality management. This paper also presents the author's attempt to integrate the fuzzy simple additive weighting method in quality management.

In future research, specialists, practitioners, as well as anyone interested are invited to perfect the quantitative methods of management and their applications in accordance with the fundamental changes in the contemporary world, and in accordance with the evolution of software in the field.

The topics approached in this paper represent a direction of study for the author and will be analyzed and presented in more detail in the monograph "Contributions to the scientific approach of quality and quality management through modeling and simulation" (in Romanian). In the monograph, the author will present a way to refine the methods used in this paper, if instead of importance coefficients of the $k_{j}$ criterion there would be used values of functions defined on intervals by the managers of the organizations. These functions may be of the form $k_{j}:\left[a_{j}, b_{j}\right] \rightarrow\left[c_{j}, d_{j}\right], k_{j}=k_{j}(t)$, where $t$ represents the time or another parameter. Thus, the function from formula (11) becomes:

$$
f_{t}: V \rightarrow R, \quad f_{t}\left(V_{i}\right)=\frac{\sum_{j=1}^{n} k_{j}(t) \mu_{i j}}{\sum_{j=1}^{n} k_{j}(t)}=\sum_{j=1}^{n} w_{j}(t) \mu_{i j}, \quad w_{j}(t)=\frac{k_{j}(t)}{\sum_{j=1}^{n} k_{j}(t)}, j=1, \ldots, n,
$$

where $t$ belongs to the time interval $\left[t_{0}, t_{1}\right]$, and $f\left(V_{i}\right)$ may be (when the integral exists):

$$
f\left(V_{i}\right)=\int_{t_{0}}^{t_{1}} \frac{\sum_{j=1}^{n} k_{j}(t) \mu_{i j}}{\sum_{j=1}^{n} k_{j}(t)} d t .
$$

\section{Acknowledgement}

This work was supported by the strategic grant POSDRU/159/1.5/S/133255, Project ID 133255 (2014), co-financed by the European Social Fund within the Sectorial Operational Program Human Resources Development 2007 - 2013.

\section{References}

1. Voinia, C.S.; Tuşa, Ana; Simion, Carmen, Quality Assurance Systems in Education and Training in Europe, Acta Universitatis Cibiniensis - Technical Series, Vol. LXIV, No. 1, pp.94-97, (2014).

2. Bucur, Amelia, Modeling as a Multiple-Criteria Decision-Making Problem and Simulation, for the Hierarchization of Programs of Study, Proceedings of the $15^{\text {th }}$ International Conference on Advances in Automatic Control Modelling and Simulation, ACMOS'13, pp.338-343, Braşov, Romania, (2013).

3. Negoiţă, C.V., Mulţimi vagi şi aplicațiile lor, Editura Tehnică, Bucureşti, (1974).

4. Gogoncea, D., Aplicarea sistemelor fuzzy în dinamica proceselor globale de standardizare în managementul calităţii(VI), Revista Calitatea-acces la succes, Year 8, No.9, pp.59-62, (2007).

5. Vlădeanu, D.; Stroie, F.; Gherasim, O., Simulări manageriale prin modelare matematică şi tehnici fuyyz. Teorie şi aplicații, Editura Performantica, Iaşi, Romania, (2008).

6. Raţiu Suciu, Camelia; Luban, Florica; Hîncu, Daniela; Ciocoiu, Carmen Nadia, Modelare economică, Editura ASE, Bucureşti, Romania, (2007).

7. Andraşiu, M.; Baciu, Aurora; Pascu, Anca; Puşcaş, Elena; Taşnadi, Al., Metode de decizii multicriteriale, Editura Tehnică, Bucureşti, Romania, (1986).

8. Saatly, T.L, The Analytic Hierarchy Process, McGraw-Hill, New York, USA (1980).

9. Resteanu, C., MADM. Teorie şi practică, Editura ICI, Bucureşti, Romania (2006).

10. Widayanti, Deni; Oka,Sudana; Arya, Sasmita, Analysis and Implementation Fuzzy Multi-Attribute Decision Making SAW Method for Selection of High Achieving Students in Faculty Level, IJCSI International Journal of Computer Science Issues, Vol. 10, Issue 1, No 2, pp.674-680, (2013). 